\title{
Resenha \\ Coletânea Direito à saúde: boas práticas e diálogos institucionais
}

Review

Collection Right to health: good practices and institutional dialogues

Reseña

Colección Derecho a la salud: buenas prácticas y diálogos institucionales

Juliane Aparecida Alves ${ }^{1}$

O compêndio é apresentado pelas palavras do presidente do Conselho Nacional de Secretários de Saúde (Conass), Leonardo Moura Vilela, que, de maneira sucinta, reflete sobre as responsabilidades temáticas da instituição, além de suas premissas funcionais e estratégias utilizadas para o cumprimento dos objetivos do Conselho, sendo uma delas as publicações de autoria coletiva, como tem ocorrido desde o ano 2015.

A publicação conta com a contribuição de servidores das secretarias estaduais de saúde; professores universitários; desembargadores; auditores do Tribunal de Contas da União (TCU); promotores de justiça; procuradores de estado; e juízes especializados em direito à saúde, que apresentam a necessidade do incremento de diálogos institucionais e das boas práticas em saúde.

Antes de se debruçar sobre o conteúdo propriamente dito, um olhar atento ao título pode apresentar proficuidade analítica: há, como em todo e qualquer discurso, certo juízo de valor indicativo do que possa vir a ser boa prática, ou seja, denota-se que a recomendação de certas práticas - as ditas úteis, corretas, institucionais, éticas, morais e legais - seja atividade factível e que atravessa todo o corpus das publicações coletadas, eixo central e pivô para esse volume da coletânea. O restante do título enfatiza a comunicação e, por que não, o questionamento dos fazeres em busca das práticas adequadas. Entende-se também que tal diálogo seja, ou deva vir a ser, uma atividade institucional, ou seja, que haja reincidência, eficácia e objetividade, características tidas como próprias de órgãos efetivos nesse partilhar de pesquisas e resultados.

O leitor é apresentado à estruturação da coletânea, em que os dois primeiros volumes

\footnotetext{
${ }_{1}^{1}$ Mestranda em Políticas Públicas em Saúde na Escola Fiocruz de Governo, Brasília, DF; graduada em Saúde Coletiva pela Universidade de Brasília, DF, Brasil. E-mail: julianealvesdoc@gmail.com
} 
discutem os levantamentos acerca da institucionalização e dos dilemas do fenômeno da judicialização, respectivamente. No terceiro volume, a ênfase é na busca de soluções atingidas pela execução de práticas exitosas e da expansão do diálogo institucional (p.12). É sempre ressaltada a real efetivação do direito à saúde, materializada pelo Sistema único de Saúde (SUS) e desafiada também pelos obstáculos impostos pelos órgãos de controle. Reitera-se, naturalmente, os agradecimentos aos autores dos 23 artigos que compõem o referido volume.

O corpus se compõe dessas partes que se comunicam, mas não necessariamente formam uma unidade de diálogo. São, para todos os efeitos, ilustrações de práticas tidas como exitosas para incentivar sua implementação no que tange à gestão de saúde e de políticas públicas, mas que também outras possam surgir em forma de publicações, pois certamente existem na prática, embora não documentadas.

Chama a atenção a nota de rodapé ao final da introdução, que isenta o trabalho de edição à totalidade de opiniões expressas nos artigos e ensaios. Por um lado, esse é um fazer recorrente em coletâneas desse porte, que ratifica a legalidade e a validade, além de assegurar à edição do Conass certa seguridade. Por outro, deixa pairar um relevante questionamento no imaginário: se o observar e o apresentar das práticas, quando pautadas por evidências e resultados adequados e apontando para práticas profícuas, não é o suficiente para o alinhamento completo com a função e a posição do Conselho, qual o parâmetro para diferenciar opinião pessoal de fato comprovado, em se tratando das práticas de saúde?

A resposta pode estar nos depoimentos e no exercício da escrita científica, que serve de ferramenta para o diálogo institucional ocorrer. $\mathrm{Na}$ tentativa de resolver essa questão, muitíssimo pertinente num contexto que envolve o diálogo e o ato comunicativo como um todo, importa levar em conta as ditas falhas de comunicação pertinentes à vida privada, mas muito relevantes quando se trata da institucionalização de práticas, regras e recomendações formais dadas por um órgão às suas secretarias. A Coletânea não recomenda, mas dá a conhecer e instiga as diferentes avaliações.

A leitura corrente dos artigos que compõem o volume indica que, no que tange às estratégias tomadas pelo SUS, quando comparadas com outros países utilizadores de sistemas universais de saúde, não há grande divergência (1). Divergem a elasticidade das 
normas, os instrumentos de gestão, a incorporação tecnológica e os ampliados, eficientes e recorrentes (logo, institucionalizados) diálogos com a sociedade.

Há de ser considerada a carteira de serviços do SUS, no sentido de dar mais institucionalidade à conferência de responsabilidade dos entes federados e outros atores. Os atores estratégicos possuem as seguintes características: (2) competência ou poder para agir ou influenciar na definição das regras que organizam o sistema, assim como na tomada de decisões. As atribuições de cada ente e ator devem ser entendidas e reforçadas, pois somente a assunção de responsabilidades é que impede a alienação ou desconhecimento.

A atuação do Tribunal de Contas da União é objeto importante na avaliação da governança da saúde pública, uma vez que suas ações têm implicações na execução da política de saúde e, portanto, na realidade social. Dentre os resultados demonstrados pelo livro comentado esteve a contribuição do TCU no que tange à orientação dos atores interferentes no SUS para que estes executem a autoavaliação e desenvolvam "maturidade em governança" (3).

A dinâmica que leva em conta a judicialização que diz respeito ao SUS parece possuir inevitável necessidade de menção, mesmo quando este não é o foco central dos estudos. De notável hibridismo entre esses temas, está a criação de um banco nacional de notas técnicas em 2016 (4), cujas premissas contemplam a descentralização; a disseminação em forma de banco de dados; e o incentivo aos mecanismos de conciliação entre gestores do sistema de saúde, além de outras partes que emergem, como as questões relacionadas à infraestrutura. Também a colisão entre as necessidades coletivas e individuais fez necessário o estudo e avaliação de processos judiciais que concernem o sistema de saúde (5), levando em conta a gestão do Estado; a não-observância dos protocolos do SUS por parte dos médicos; e a busca irrestrita por lucros, característica da indústria farmacêutica. Para tratar algumas dessas questões, a solução encontrada pela SES-SP foi um acervo informatizado (6), a partir de software que fornece indicadores e relatórios aos gestores, e evidencia o "flagrante desarranjo nos limites da responsabilidade" ( $p .70)$ de cada esfera governamental. Cite-se a especialização de procuradores, na Procuradoria-Geral do Estado do Paraná (PGE-PR) (7), quando ocorreu aumento exponencial da chamada judicialização do direito à saúde. Especificamente sobre os conceitos e as problemáticas desta e, de maneira coesa, sobre como os diálogos institucionais e as boas práticas interagem 
diretamente com a sutura de tal judicialização, certa passagem discorre:

se faz necessária a criação de mecanismos de constante atualização de informações inerentes às demandas judiciais, compartilhadas entre os diversos atores e setores envolvidos na garantia do direito à saúde. Outro aspecto está vinculado à viabilização do acesso a informações e análises, ampliando o leque de possibilidades de ações do gestor na análise de situação, planejamento, programação, monitoramento e avaliação de suas ações. (8, p.101)

Aqui transliterou-se por atestar grande retidão e credibilidade a essa constatação, que resume de maneira eficiente a complexa teia relacional que se dá entre os entes envolvidos e os processos: a gestão precisa ser ativa em relação à resolução de problemas (9) e à divulgação de resultados (e a consequente alteração de condutas quando não se mostrarem satisfatórias), o que torna necessário e obrigatório o processo organizacional (aqui usado como sinônimo de institucional) em sua feitura como mecanismo de controle e transparência social. Interna a essa transparência (10), um resultado preponderante menciona as relações público-privadas e aconselha a obrigatoriedade na transparência quanto às doações realizadas aos profissionais e aos entes de saúde. Por meio de um inventivo sistema chamado DeclaraSus, elaborado em 2018, o usuário avalia a atuação do profissional tendo em mãos tais doações, e analisa a influência dos interesses privados no atendimento, assim como o gestor tem a capacidade de analisar os impactos da atuação das empresas nas políticas públicas e demandas judiciais (p.126).

A debilidade do financiamento (11), logísticas de acesso e ineficiência na alocação de serviço, no caso das comunidades indígenas (13) e a inefetividade ocasional na execução dos direitos à saúde prescrita na Constituição Federal (15) são alguns das muitas boas práticas. De maneira menos informal, há de se considerar que, diante de uma realidade problemática, as muitas soluções sugeridas e experimentadas são solos férteis para a emergência de boas práticas. Extrapolando esse raciocínio, quando não há impasses, não pode haver resoluções. Várias publicações compiladas permeiam o sucesso de políticas e iniciativas postas a teste em condições quase sempre adversas e estagnadas, o que nunca deixa de fornecer uma expectativa, mesmo que altamente científica, bastante positivista em relação à realidade.

Orientações e manuais, exemplificados e guiados, até um tanto tautologicamente (já que um fazer coletivista que vise abarcar todo o território nacional preconiza manuais-guia 
para feitura de manuais-guia), decorrem em viés crítico e problematizador durante toda a coletânea. A elevação dos resultados esperados passa pela sistematização e consolidação de regras (12), que fazem efeito real a partir do momento em que são acessíveis e consultáveis pelos agentes públicos, além de, caso resulte em transparência institucional, pelos usuários. É, como sabe-se, rotineiro das práticas que concernem a administração pública, o levante de regras e, possivelmente, generalizações, visto que o processo de regrar deve levar em conta o contexto de aplicação das mesmas.

Mesmo que consideremos o Brasil como possuidor de muitíssimas peculiaridades, não há desserviço em exercício comparativo com relação à compreensão de tais regras em outros cenários, como em Portugal (14), e observou-se que, em se tratando de segurança do paciente, por exemplo, o ponto convergente é a estruturação de métodos educativos, de monitoramento e de prevenção. A apresentação de estudos segue-se, de recomendação da criação de comitês locais (16) que visa lidar com a dinâmica micro/macro em etapas institucionais bem definidas e cientes, em resposta à judicialização da saúde, revelando a necessidade de harmonização de diversos critérios de avaliação, o que acarreta em encaminhamentos administrativos mais conscientes. A otimização dos processos de trabalho da equipe (18) também é levantada, em vias de garantir o acesso à prevenção e diagnóstico precoce, principalmente quanto às doenças crônicas e às endemias (17). Ainda assim, existem dúvidas a respeito de como a formação de atitudes exequíveis podem nos levar a considerar a reestruturação das regras de conduta normativas, além da forma como essas condutas chegam nas equipes, ou seja, no processo de formação, que deveria ser continuado, em parâmetro ideal.

Diante da mortalidade em casos de condicionantes específicos (19) e de um cenário coletivo e potencialmente problemático, fruto de uma série de fatores, entre elas a estrutura estatal que se ampara em um também problemático presidencialismo de coalizão (20), somos guiados levemente à noção pouco tangível, mas largamente conhecida, de que as relações local/global, público/privado e individual/coletivo estão novamente no cerne da questão humana, regidas por dinâmicas próprias e observáveis, sempre acessíveis para o pesquisador, mas repletas de detalhes e pormenores se postas diante de óticas mais interventivas. É no diálogo que essas questões parecem ser novamente mais alcançáveis, e a coletânea continua por formar um corpus de estudos que aponta para os êxitos nessa 
esfera, cada uma a seu modo, como exige a peculiaridade de cada caso. O contemporâneo não poupa nossas limitações, e formas ainda mais modernas de atendimento se mostram enquanto ferramenta: pode-se levar em conta, por exemplo, (21) a sequenciação genômica ao reconhecermos as vantagens demonstradas pelo tratamento médico personalizado sobre esse eixo. A problemática envolve a responsabilização de mais entes, além do reconhecimento e seguridade de direitos básicos do paciente, uma vez que a questão levantada traz consigo diversas questões étnico-jurídicas (p.269). É visível, diante disto, o modo pelo qual o desafiador cenário globalizado não pode mais se dissociar de diretrizes de desenvolvimento em qualquer área, a saúde não se encaixando como exceção desse panorama.

O contemporâneo também é acometido pelas mesmas problemáticas que a informação e a comunicação, e, ao falarmos da fomentação de diálogos institucionais, deve haver o fortalecimento da coerência, democracia e participação, além dos princípios fundamentais do sistema universal de saúde: a partir do momento em que nos damos conta que o processo informativo em saúde é, sobretudo, um processo informativo, o que determina que todas as circunstâncias que afetam o segundo necessariamente afetam 0 primeiro. Desvendar tal processo é fundamental e estratégico para alcançar resultados satisfatórios (22). Diante disso, e da complexidade da sociedade atual, as ações de promoção, proteção e recuperação da saúde jamais devem estar desconexas de um fazer comunicativo eficiente. Esse processo dialógico parece-nos culminar em um fazer de enfrentamento diante dos obstáculos da comunicação e um eficiente solucionador parece, mais de uma vez, ser o sistema digital. A configuração do NatJus (23), enquanto canal de disseminação de conhecimento judiciário acerca do SUS, é ferramenta da gestão pública na identificação e resolução diversos entraves, entre eles a efetivação da oferta de ações e a alocação dos serviços de saúde ao usuário. Considerou-se o constante crescimento das demandas judiciais referentes à ação da saúde, provável motivador do volume anterior desta coletânea, o que enaltece a notoriedade e importância da criação e atuação do referido sistema digital.

Talvez o grande crédito possuído pelo referido volume da coletânea se estabelece na agradável leitura temática, recortada por uma ordem coerente dos artigos, formando um todo que se faz por partes, ao mesmo tempo independentes e interdependentes no diálogo sobre 
o diálogo, de difusão e disseminação de metodologias que se perfazem sobre si mesmas quando estão em conjunto e no que se refere à especulação de uma coerência nacional de estratégias de gestão de um sistema rico e complexo como o sistema universal de saúde.

\section{Referências}

1. Amaral MA. Conversações para a Ação: Um Desafio a Superar para o Fortalecimento do SUS. Coletânea direito à Saúde: Boas Práticas e Diálogos Institucionais. Brasília. CONASS; 2018. p. $12-21$.

2. Dutra RAA. A Definição de Competências no Diálogo Institucional no SUS. Ibidem. p. 2233.

3. Ferreira AMA, Lira JM, Chaves MABR. A Contribuição da Governança para Aprimorar o Uso dos Recursos na Saúde Pública. Ibidem. p. 34-47.

4. Junior AH, Rocha RS. O Judiciário e a Questão da Saúde: a Busca de uma Judicialização Qualificada e de Soluções Negociadas - um Projeto do Fórum da Saúde do Conselho Nacional de Justiça. Ibidem. p. 48-55.

5. Domingues DC, Barbosa MM. Utilização das Notas Técnicas nos Processos Judiciais do Estado de Minas Gerais. Ibidem. p. 56-69.

6. Siqueira PSF, Martinsa MA, Domingues R. S-CODES - Sistema Informatizado para o Trato da Judicialização. Ibidem. p.70-82.

7. Faglioni AF, Castelo FA. A Especialização das Procuradorias dos Estados nas Questões Relativas ao Direito à Saúde como Instrumento Eficaz na Defesa dos Entes Estaduais: A Experiência da PGE/PR. Ibidem. p. 84-90.

8. Carvalho ALB, Ouverney AM, Carvalho NGO. Judicialização na Saúde: Aspectos Conceituais, Reflexões e Caminhos para uma Proposta de Avaliação. Ibidem. p. 92-104.

9. Lemos ANLE, Lima JAO, Aranha MI. Processo de Consolidação SUSLegis: Discussões do Desenho Metodológico. Ibidem. p. 106-115.

10. Marques AJS, Dutra RAA. Conflito de Interesse: Transparência para Ficar Legal. Ibidem. p. 116-127.

11. Gomides EFC. Implantação do Primeiro Consórcio Intermunicipal da Saúde no Estado de Goiás. Ibidem. p. 128-139.

12. Oliveira RB, Castro RGL. Sesacre Legis: Banco de Normas da Secretaria de Estado de Saúde do Acre. Ibidem. p. 140-152. 
13. Taveira ZZ, Scalco N, Ferreira LB. O Subsistema de Atenção à Saúde Indígena e a Integralidade da Atenção à Saúde. Ibidem. p. 154-167.

14. Alves SMC, Pereira AGD, Delduque MC. Segurança do Paciente: Aspectos Comparativos entre Brasil e Portugal. Ibidem. p. 168-182

15. Schramm LC, Sousa MN, Lima MCF. Efetividade do Acesso aos Serviços de Saúde de Oncologia no Estado do Maranhão. Ibidem. p. 184-194.

16. Schulze M. A Desjudicialização da Saúde no Rio Grande do Sul: Cabal Redução do número das Ações Ativas e Estratégia e Interiorização. Ibidem. p. 196-208.

17. Ferreira JG, Lima CHF, Araujo JC. Educação Permanente em Atenção Ontológica: Estratégia de Gestão para Aprimoramento dos Processos de Trabalho nos Serviços de Saúde no Estado do Maranhão. Ibidem. p. 210-221.

18. Moraes RS. Uma Síntese do Fomento ao Desenvolvimento Harmônico e Sustentável Via Atuações Resolutivas, Principalmente as Atuações Resolutivas de Planejamento e de Gestão Sistêmicos, de Negociação, de Mediação e de Conciliação (DHS via PGS e NMC). Ibidem. p. 222-234.

19. Lopes LT, Amaral TCL. Aumento da Mortalidade por Acidentes Envolvendo Motociclistas no Brasil, Associado ao Processo de Massificação do Uso de Motocicletas e à Baixa Eficiência das Políticas Públicas Federais no Enfrentamento dessa Escalada. Ibidem. p. 236247.

20. Bem IP, Delduque MC. Presidencialismo de Coalizão: uma Revisão Narrativa da Literatura 2013-2017. Ibidem. p. 248-258.

21. Figueiredo EAS, Campos JFS, Pereira AGD. Desafios Jurídicos da Medicina Personalizada. Ibidem. p. 260-271.

22. Amaral TCL. Informação, Educação e Comunicação em Saúde no Mundo Contemporâneo: Religando os Conhecimentos Segundo o Conhecimento Complexo. Ibidem. p. 272-279.

23. Henrique MC, Mendonça MRL, Braga EA. NatJus e Desjudicialização da Saúde. Ibidem. p.280-291. 